\title{
On the Specification of the Gravity Model of Trade: Zeros, Excess Zeros and Zero-Inflated Estimation
}

\author{
Martijn J. Burger, Frank G. van Oort, and Gert-Jan M. Linders
}

Accepted and forthcoming in Spatial Economic Analysis

\begin{tabular}{|l|l|}
\hline \multicolumn{2}{|l|}{ ERIM REPORT SERIES RESEARCH IN MANAGEMENT } \\
\hline ERIM Report Series reference number & ERS-2009-003-ORG \\
\hline Publication & January 2009 \\
\hline Number of pages & 42 \\
\hline Persistent paper URL & http://hdl.handle.net/1765/14614 \\
\hline Email address corresponding author & mburger@ese.eur.nl \\
\hline Address & Erasmus Research Institute of Management (ERIM) \\
& RSM Erasmus University / Erasmus School of Economics \\
& Erasmus Universiteit Rotterdam \\
& P.O.Box 1738 \\
& 3000 DR Rotterdam, The Netherlands \\
& Phone: + 31 10 408 1182 \\
& Fax: $\quad+31104089640$ \\
& Email: info@erim.eur.nl \\
& Internet: $\quad$ www.erim.eur.nl \\
\hline
\end{tabular}

Bibliographic data and classifications of all the ERIM reports are also available on the ERIM website: www.erim.eur.nl 


\section{ERASMUS RESEARCH INSTITUTE OF MANAGEMENT}

\section{REPORT SERIES}

\section{RESEARCH IN MANAGEMENT}

\begin{tabular}{|l|l|}
\hline ABSTRACT AND KEYWORDS \\
\hline Abstract & $\begin{array}{l}\text { Conventional studies of bilateral trade patterns specify a log-normal gravity equation for } \\
\text { empirical estimation. However, the log-normal gravity equation suffers from three problems: the } \\
\text { bias created by the logarithmic transformation, the failure of the homoscedasticity assumption, } \\
\text { and the way zero values are treated. These problems normally result in biased and inefficient } \\
\text { estimates. Recently, the Poisson specification of the trade gravity model has received attention } \\
\text { as an alternative to the log-normality assumption (Santos Silva and Tenreyro, 2006). However, } \\
\text { the standard Poisson model is vulnerable for problems of overdispersion and excess zero flows. } \\
\text { To overcome these problems, this paper considers modified Poisson fixed-effects estimations } \\
\text { (negative binomial, zero-inflated). Extending the empirical model put forward by Santos Silva } \\
\text { and Tenreyro (2006), we show how these techniques may provide viable alternatives to both the } \\
\text { log-normal and standard Poisson specification of the gravity model of trade. }\end{array}$ \\
\hline international trade, distance, gravity model, modified Poisson models \\
\hline Free Keywords & $\begin{array}{l}\text { The ERIM Report Series is distributed through the following platforms: } \\
\text { Academic Repository at Erasmus University (DEAR), DEAR ERIM Series Portal } \\
\text { Social Science Research Network (SSRN), SSRN ERIM Series Webpage } \\
\text { Research Papers in Economics (REPEC), REPEC ERIM Series Webpage }\end{array}$ \\
\hline Classifications & $\begin{array}{l}\text { The electronic versions of the papers in the ERIM report Series contain bibliographic metadata } \\
\text { by the following classification systems: } \\
\text { Library of Congress Classification, (LCC) LCC Webpage } \\
\text { Journal of Economic Literature, (JEL), JEL Webpage } \\
\text { ACM Computing Classification System CCS Webpage } \\
\text { Inspec Classification scheme (ICS), ICS Webpage }\end{array}$ \\
\hline
\end{tabular}




\title{
On the Specification of the Gravity Model of Trade: Zeros, Excess Zeros and Zero-Inflated Estimation
}

\section{Martijn J. Burger}

Corresponding author: Department of Applied Economics, Erasmus University Rotterdam, P.O. Box 1738, 3000 DR Rotterdam. Tel: +31 (0)10 4089579. Fax: +31 (0)10 4089141.

E-mail: mburger@few.eur.nl.

Frank G. van Oort

Department of Economic Geography, Utrecht University and Environmental Assesment Agency. E-mail: f.vanoort@geo.uu.nl.

Gert-Jan M. Linders

Department of Spatial Economics, Free University Amsterdam.

E-mail: glinders@feweb.vu.nl.

\begin{abstract}
Conventional studies of bilateral trade patterns specify a log-normal gravity equation for empirical estimation. However, the log-normal gravity equation suffers from three problems: the bias created by the logarithmic transformation, the failure of the homoscedasticity assumption, and the way zero values are treated. These problems normally result in biased and inefficient estimates. Recently, the Poisson specification of the trade gravity model has received attention as an alternative to the log-normality assumption (Santos Silva and Tenreyro, 2006). However, the standard Poisson model is vulnerable for problems of overdispersion and excess zero flows. To overcome these problems, this paper considers modified Poisson fixed-effects estimations (negative binomial, zero-inflated). Extending the empirical model put forward by Santos Silva and Tenreyro (2006), we show how these techniques may provide viable alternatives to both the log-normal and standard Poisson specification of the gravity model of trade.
\end{abstract}

Keywords: International trade, distance, gravity model, modified Poisson models JEL Classification: C13, C21, F15 


\section{The Gravity Model of Trade and the Log-Normal Specification}

Spatial interaction patterns, such as international trade, migration or commuting flows, can be predicted and elucidated with an analogy to Newton's law of universal gravitation. The gravity model, which has been used in modern economics since Isard (1954), Ullman (1954), and Tinbergen (1962), hypothesizes that the gravitational force between two objects is directly proportional to the product of the masses of the objects and inversely proportional to the geographical distance between them. Over the years, this model has become popular in international economics when analyzing the pattern of trade flows between countries (Eichengreen and Irwin, 1998; Overman et al., 2004). ${ }^{\mathrm{i}}$ In its most elementary form, the gravity model can be expressed as

$$
I_{i j}=K \frac{M_{i}^{\beta_{1}} M_{j}^{\beta_{2}}}{d_{i j}^{\beta_{3}}},
$$

where $I_{i j}$ is the interaction intensity or the volume of trade between countries $i$ and $j, K$ is a proportionality constant, $M_{i}$ is the mass of the country of origin (in applications to bilateral trade patterns usually reflected by the country's GDP), $M_{j}$ is the mass of the country of destination, $d_{i j}$ is the physical distance between the two countries, $\beta_{1}$ is the potential to generate flows, $\beta_{2}$ is the potential to attract flows, and $\beta_{3}$ is an impedance factor reflecting the distance decay in trade. This basic model can easily be augmented to include other variables, such as whether countries $i$ and $j$ share borders, have the same language, or are member of a regional integration agreement (Feenstra, 2004). 
Taking logarithms of both sides of the equation and adding a random disturbance term, the multiplicative form (1) can be converted into a linear stochastic form, yielding a testable equation:

$\ln I_{i j}=\ln K+\beta_{1} \ln M_{i}+\beta_{2} \ln M_{j}-\beta_{3} \ln d_{i j}+\varepsilon_{i j}$,

where $\varepsilon_{i j}$ is assumed to be independent and identically distributed (i.i.d.). Equation (2) is in the trade literature better known as the traditional or empirical gravity model (e.g., Eichengreen and Irwin, 1998) and in the field of regional science as the unconstrained gravity model (e.g., Fotheringham and O'Kelley, 1989; Sen and Smith, 1995). The terminology used in the field of regional science reflects that the model does not take into account the constraints that the estimated bilateral outflows should add up to the total outflows, and that the estimated bilateral inflows should add up to the total inflows.

Recently, the international trade literature has shown a renewed interest in the theoretical foundations of the gravity model. This has resulted in formulations of the gravity model that derive from general equilibrium modeling of bilateral trade patterns (Bröcker, 1989; Eaton and Kortum, 2002; Anderson and Van Wincoop, 2003; Feenstra, 2004). One of the key insights in the recent contributions to this field is that the traditional specification of the gravity model suffers from omitted variable bias, as it does not take into account the effect of relative prices on trade patterns. As shown by Anderson and Van Wincoop (2003), bilateral trade intensity not only depends on bilateral trade costs (affected by spatial distance, language differences, trade restrictions, and the like), but also on GDP-share average weighted multilateral trade costs indices or "multilateral resistance terms" (affecting the prices of 
import-competing goods in the importing country, as well as export opportunities in the origin country). Omitting these terms from the specification may result in an omitted variables bias on the remaining parameter estimates in the gravity model. Essentially, this extension of the gravity model is analogous to the earlier literature in the field of regional science, which motivates singly or doubly constrained gravity models that satisfy the constraints on total country-specific inflows and outflows (see, e.g., Fotheringham and O’Kelly, 1989; Bröcker, 1989).

As shown by Anderson and Van Wincoop (2003) and Feenstra (2004) and in analogy to earlier work by Bröcker and Rohweder (1990), a country-specific fixed-effects specification of the gravity equation is in line with the theoretical concerns regarding the correct specification of the model and yields consistent parameter estimates for the variables of interest. This is again in analogy to the above-mentioned regional science literature. ${ }^{\text {ii }}$ In a cross-sectional setting, this implies including country-specific exporter and importer dummy variables in equation (2). More formally, the log-normal fixed effects specification of the most basic gravity model (including physical distance as only resistance to trade) would look as follows:

$\ln I_{i j}=\beta_{3} \ln d_{i j}+\gamma_{i}+\eta_{j}+\varepsilon_{i j}$,

where $\gamma_{i}$ is the fixed effect of the country of origin (the exporter) and $\eta_{j}$ is the fixed effect of the country of destination (the importer). As this is commonly accepted, we will apply this estimation procedure as well. 
The recent theoretical and methodological developments in the applied empirical trade literature have also increased the awareness for a different set of specification issues, that have at their heart the often implicit assumption of log-normality in the random error component, hence the double-logarithmic specification of the gravity equation to be estimated. The main catalyst of the latter development was the question of how to deal with zero-valued trade flows in estimating the gravity equation parameters (see, e.g., Santos-Silva and Tenreyro, 2006; Linders and De Groot, 2006; Helpman et al., 2008). This issue has not reached a commonly accepted solution yet, and we will address this discussion by further investigating the (fixed-effects) specification and estimation problems related to zero-valued bilateral trade flows.

In the remainder of this paper, we first discuss the underlying problems of the log-normal specification in section 2. Section 3 discusses the alternative to use a Poisson specification of the gravity model, as is common in count data applications, and raises a number of potential pitfalls of this specification in trade flow applications. We propose to contrast the standard Poisson solution against alternative members of the Poisson family: the zero-inflated Poisson model and other modified Poisson models that can correct for the potential problems associated with the standard Poisson model. Section 4 provides an empirical application of these different econometric specifications to the analysis of bilateral trade patterns. Using this specific context, we compare the modified Poisson estimators to standard Poisson outcomes as well as to a more conventional OLS benchmark, both in terms of model fit and ability to control for specification problems. In doing so, we contribute to the methodological discussions on the correct specification of the trade gravity model by further investigating the fixed effects specification and estimation problems related to zero-valued bilateral trade flows. Section 5 concludes this paper and provides directions for further research. 


\section{Problems with the Log-Normal Specification of the Gravity Model}

Until now, the log-normal formulation of the gravity model has been the most commonly used economic tools to investigate international bilateral trade flows. However, from a methodological point of view, there are some serious problems with this gravity model specification. Flowerdew and Aitkin (1982) specifically point to (1) the bias created by the logarithmic transformation, (2) the failure of the assumption that all error terms have equal variance, and (3) the sensitivity of research results to zero-valued flows. These problems will be discussed in more detail below. In particular, we will focus on the problem of zero values in the log-normal gravity (fixed-effects) model.

First, the logarithmic transformation has an effect on the nature of the estimation process, as the $\log$-normal model generates estimates of $\ln I_{i j}$ but not of $I_{i j}$. As Haworth and Vincent (1979) have shown, the antilogarithms of these estimates tend to be biased, which in turn can lead to underpredicting of large trade flows and total trade flows (Flowerdew and Aitkin, 1982). Although it is well known in economics that Jensen's inequality implies that $E\left(\ln I_{i j}\right) \neq \ln E\left(I_{i j}\right)$ and that the concavity of the $\log$ function should create a downward bias when using OLS, insufficient attention has been paid to this drawback of the log-normal model in the study of bilateral trade (see also Santos Silva and Tenreyro, 2006).

Second, the log-normal model is based on the questionable assumption that the error terms all have the same variance for all pairs of origins and destinations (homoskedasticity). Hence, it is assumed that an observed flow of 1 in relation to an expected flow of 2 is as probable as an observed flow of 1000 in relation to an expected flow of 2000 (Flowerdew and Aitkin, 1982). 
Especially when there are a large number of cases in which the observed and expected flows are small, small absolute differences before performing a logarithmic transformation of the dependent and independent variables may lead to large differences in the log-normal estimation of the model (Flowerdew and Aitkin, 1982). In the presence of such heteroskedasticity, not only the efficiency but also the consistency of the estimators is at stake (Santos Silva and Tenreyro, 2006).

Third, the log-normal model cannot deal well with zero-valued trade flows, since the logarithm of zero is undefined. Frankel (1997) argues that the most obvious reason for the occurrence of zero-valued trade flows is the lack of trade between small and distant countries, which can at best be explained by large associated variables and fixed costs. Rauch (1999) further points out the low levels of GDP per capita and the lack of cultural and historical links as possible explanations for the absence of trade between countries, while Ghazalian et al. (2007) point to the influence of policies. This list of possible reasons for the existence of zero-valued trade flows becomes even longer if the volume of trade in a specific good, rather than the volume of overall trade, between two countries is considered. All countries do not produce all available goods, nor do they all have an effective demand for all available goods. Using bilateral trade data from 1990 from the World Trade Database (WTDB), Haveman and Hummels (2004) reported that in $58 \%$ of the cases, trade in a specific good originates from fewer than $10 \%$ of all countries. Similar patterns could be observed in other years and in other bilateral trade data, such as the UN COMTRADE dataset. On a similar note, Haveman and Hummels (2004) found that almost all countries (99.4\%) bought goods from less than half of the 438 distinguished sectors. According to Haveman and Hummels (2004), a major weakness of the specification of the gravity model is therefore that it implies trade among all countries in all goods. 
By tradition, the most common strategies to circumvent the 'zero problem' in the analysis of trade flows are to omit all zero-valued trade flows or arbitrarily add a small positive number (usually 0.5 or 1 ) to all trade flows in order to ensure that the logarithm is well-defined (Linders and De Groot, 2006). But by deleting all zero-valued flows, important information on low levels of trade is left out of the model (Eichengreen and Irwin, 1998). Particularly, when these zero-valued flows are non-randomly distributed, this can lead to biased results. Hence, a truncation of the sample should be avoided at all means. Likewise, the strategy of substituting zeros by a small positive constant can be regarded as inadequate. As Linders and De Groot (2006) remark, the choice of this number to be added is usually arbitrary and lacks both theoretical and empirical justification. What's even worse, Flowerdew and Aitkin (1982) find that even small differences in the selected constant can distort research results seriously. Varying the constant between 0.01 and 1, they show that the predicted interaction intensity significantly declines with the size of the constant, while the values of the regression coefficients generally decrease. In fact, King (1988) demonstrates that you can generate any parameter estimate to your liking by playing around with the size of the constant.

\section{Poisson and Modified Poisson Specifications of the Gravity Model}

\subsection{From a Log-Normal to a Poisson Specification}

Given the problems with the log-normal specification, the use of alternative regression techniques could be more appropriate in the context of the gravity model. However, despite repeated warnings from the related fields of quantitative geography and regional science (e.g., Senior, 1979; Flowerdew and Aitkin, 1982; Lovett and Flowerdew, 1988; Fotheringham and O'Kelley, 1989; Bohara and Krieg, 1996), international economics has only recently begun to take this issue seriously (e.g., Haveman and Hummels, 2004; Linders 
and De Groot, 2006; Santos Silva and Tenreyro, 2006; Helpman et al., 2008). Following the increasing resistance against using the log-normal model in bilateral trade analysis, attention has been given to the possible use of Poisson and modified Poisson models (e.g., Santos Silva and Tenreyro, 2006). ${ }^{\text {iii }}$ This family of models originally derives from the analysis of count data. However, as indicated by Wooldridge (2002), the Poisson estimator can also be applied to non-negative continuous variables. In this article, we will focus on the application of negative binomial and zero-inflated models (Long, 1997) in gravity trade models, which can be considered modified Poisson models. As will be shown later in this article, this class of models is, from both a theoretical and empirical point of view, a viable alternative to standard Poisson and its log-normal counterpart.

By applying the Poisson specification to the fixed effects specification of the gravity model of trade (Andersen and Van Wincoop, 2003), we state that the observed volume of trade between countries $i$ and $j$ has a Poisson distribution with a conditional mean $(\mu)$ that is a function of the independent variables (3). As $I_{i j}$ is assumed to have a non-negative integer value, the exponential of the independent variables is taken, so as to ensure that $\mu_{i j}$ is zero or positive. More formally,

$$
\operatorname{Pr}\left[I_{i j}\right]=\frac{\exp \left(-\mu_{i j}\right) \mu_{i j}{ }^{I_{i j}}}{I_{i j} !},\left(I_{i j}=0,1 \ldots\right)
$$

Here, the conditional mean $\mu_{i j}$ is linked to an exponential function of a set of regression variables, $X_{i j}$ : 


$$
\mu_{i j}=\exp \left(\alpha_{0}+\beta^{\prime} X_{i j}+\eta_{i}+\gamma_{j}\right)
$$

where $\alpha_{0}$ is a proportionality constant, $X_{i j}$ is the $1 \mathrm{x} k$ row vector of explanatory variables with corresponding parameter vector $\beta$, which represent the different dimensions of transactional distance (cf. Obstfeld and Rogoff, 2000) between countries (e.g., physical distance, language and institutional distance). $\eta_{i}$ is an effect specific to the country of origin (an exporter-specific effect), and $\gamma_{j}$ is an effect specific to the country of destination (an importer-specific effect). The fixed-effects estimation in the model controls for countryspecific fixed effects related to importers and exporters. Note that the Poisson model assumes equidispersion $\left(E\left(T_{i j} \mid x\right) \propto V\left(T_{i j} \mid x\right)\right)$, as the conditional variance of the dependent variable should be equal to its conditional mean.

In contrast to the log-normal specification, the Poisson specification of the gravity model does not face the problems outlined in the previous section. First, the linking function is loglinear instead of log-log. Hence, the Poisson regression model generates estimates of $I_{i j}$ and not of $\ln I_{i j}$, thereby avoiding underpredicton of large trade flows and the total volume of trade. In addition, as the Poisson regression model is estimated by a maximum likelihood method, the estimates are adapted to the actual data, which means that the sum of the predicted values is virtually identical to the sum of the input values. Second, Poisson regression estimates are consistent in the presence of heteroskedasticity and are reasonably efficient, especially in large samples (King, 1988). Third, because of its multiplicative form, the Poisson specification provides a natural way to deal with zero-valued trade flows. 


\subsection{Overdispersion and the Negative Binomial Specification}

An important condition of the Poisson model is that it assumes equidispersion. However, the conditional variance is most often higher than the conditional mean, which means that the dependent variable is overdispersed. According to Greene (1994), an important reason why we frequently find more variation than expected is the presence of unobserved heterogeneity not taken into account by the Poisson regression model. In fact, the Poisson regression model only accounts for observed heterogeneity, where different values of the predictor variables result in a different conditional mean value. Unobserved heterogeneity, however, originates from omitted variables. Not correcting for over- or underdispersion normally results in consistent, yet inefficient, estimation of the dependent variable, which is exemplified by spuriously large z-values and spuriously small p-values due to downward biased standard errors (Gourieroux et al., 1984; Cameron and Trivedi, 1986).

In order to correct for overdispersion, a negative binomial regression model (4), which belongs to the family of modified Poisson models, is most frequently employed. This can be regarded as a modification of the Poisson regression model (Greene, 1994). The expected value of the observed trade flow in the negative binomial regression model is the same as for in Poisson regression model (Long, 1997), but the variance here is specified as a function of both the conditional mean $(\mu)$ and a dispersion parameter $(\alpha)$, thereby incorporating unobserved heterogeneity into the conditional mean. In other words, an additional error term has been added to the negative binomial regression model. By allowing the dispersion parameter to take on other values than 1 , overdispersion can be taken care of by explicitly modeling between-subject heterogeneity. More formally, 


$$
\operatorname{Pr}\left[I_{i j}\right]=\frac{\Gamma\left(I_{i j}+\alpha^{-1}\right)}{I_{i j} ! \Gamma\left(\alpha^{-1}\right)}\left(\frac{\alpha^{-1}}{\alpha^{-1}+\mu_{i j}}\right)^{\alpha^{-1}}\left(\frac{\mu_{i j}}{\alpha^{-1}+\mu_{i j}}\right)^{I_{i j}},
$$

where $\mu_{i j}=\exp \left(\alpha_{0}+\beta^{\prime} X_{i j}+\eta_{i}+\gamma_{j}\right), \Gamma$ is the gamma function, and $\alpha$ is a parameter that determines the degree of dispersion in predictions, hereby allowing the conditional variance to exceed the conditional mean. The larger $\alpha$ is, the larger the degree of overdispersion in the data. A likelihood ratio test of $\alpha$ can be employed to test whether the negative binomial distribution is preferred over a Poisson distribution (Cameron and Trivedi, 1986). If $\alpha$ is approximately zero, the negative binomial regression model reduces to the Poisson regression model.

\subsection{Excess Zeros and the Hurdle and Zero-Inflated Specification}

A related problem stems from the excessive number of zeros in the data, meaning that the number of zeros is greater than the Poisson or negative binomial distribution predicts. Although an excessive number of zeros may 'masquerade' as overdispersion, it is, according to Greene (1994), important to separate these two issues into different processes underlying the deficiencies of the Poisson model. Whereas overdispersion is induced from unobserved individual heterogeneity, excess zeros derive from 'non-Poissonness' (cf. Johnson and Kotz, 1969) through an overabundance of zeros (Greene, 1994). Although both the Poisson model and the negative binomial regression model can, unlike the log-normal model, technically deal with zeros, they are not well suited to handle the situation in which the number of observed zeros exceeds the number of zeros predicted by the model. The most important cause of 'non-Poissonness' is that some zeros in the data are produced by a different process than the remaining counts (including some of the other zeros), e.g., the complete lack of trade 
between pairs of countries because of a lack of resources (in which case the trade probability is identically zero by definition), compared to the lack of trade between pairs of countries due to the distances and differences in preferences and specializations (in which case the trade probability is theoretically different from zero).

The zero-inflated model (Lambert, 1992; Greene, 1994; Long, 1997) considers the existence of two latent groups within the population: a group having strictly zero counts and a group having a non-zero probability of having counts other than zero. Correspondingly, the estimation process of the zero-inflated Poisson model consists of two parts (5.1 and 5.2). The first part of the zero-inflated model contains a logit (or probit) regression of the probability that there is no bilateral trade at all. The second part contains a Poisson regression (5.1.2) of the probability of each count for the group that has a non-zero probability or interaction intensity other than zero. Unlike the negative binomial model, zero-inflated models can change the mean structure of the original Poisson model by explicitly modeling the origin of zero counts (Long, 1997). More formally,

$\operatorname{Pr}\left[I_{i j}\right]=\psi_{i j}+\left(1-\psi_{i j}\right) \exp \left(-\mu_{i j}\right)$

$\operatorname{Pr}\left[I_{i j}\right]=\left(1-\psi_{i j}\right) \frac{\exp \left(-\mu_{i j}\right) \mu_{i j}^{I_{i j}}}{I_{i j} !}$

in which, $\mu_{i j}=\exp \left(\alpha_{0}+\beta^{\prime} X_{i j}+\eta_{i}+\gamma_{j}\right)$ and $\psi_{i j}$ is the proportion of observations with a strictly zero count $\left(0 \leq \psi_{i j} \leq 1\right)$, which is determined by a logit model. Note that when $\psi_{i j}$ is 0, the zero-inflated Poisson model reduces to the Poisson model. The zero-inflated negative binomial regression model (6) is defined in a similar fashion: 


$$
\begin{aligned}
& \operatorname{Pr}\left[I_{i j}=0\right]=\psi_{i j}+\left(1-\psi_{i j}\right)\left(\frac{\alpha^{-1}}{\alpha^{-1}+\mu_{i j}}\right)^{\alpha^{-1}} \\
& \operatorname{Pr}\left[I_{i j}\right]=\left(1-\psi_{i j}\right) \frac{\Gamma\left(I_{i j}+\alpha^{-1}\right)}{I_{i j} ! \Gamma\left(\alpha^{-1}\right)}\left(\frac{\alpha^{-1}}{\alpha^{-1}+\mu_{i j}}\right)^{\alpha^{-1}}\left(\frac{\mu_{i j}}{\alpha^{-1}+\mu_{i j}}\right)^{I_{i j}}
\end{aligned}
$$

For both the zero-inflated Poisson model and the zero-inflated negative binomial regression model, the Vuong statistic (Vuong, 1989) can be employed to test whether a zero-inflated model is favored above its non-zero inflated counterpart by examining whether significant evidence for excessive zero counts exists. The likelihood ratio test of overdispersion can be used to test whether the negative binomial specification or the Poisson specification.

A zero-inflated model may be more appropriate to model trade flows, both when viewed from a methodological and a theoretical point of view. For example, there is a difference between scientists who do not write any papers or and hence do not receive citations, and scientists who do write papers but are still not cited. Similar to the latter situation, zeroinflated trade models take into account that not all pairs of countries have the potential (or are at risk) to trade because of trade embargos or a severe mismatch between demand and supply. On a similar note, the geographical or cultural distance between countries may simply be too large for trade to be profitable. Hence, the profitability of trade, which reflects the trade potential, can be separated from the volume of trade as stemming from two different processes. Although both processes may depend on the same variables, as the profitability will generally rise if the potential size of trade gets larger (and vice versa), this does not imply that profitability only reflects the potential size of the flow. In fact, some variables may 
be more important in determining the profitability of bilateral trade rather than the potential volume of bilateral trade.

In this respect, the zero-inflated model resembles the hurdle Poisson regression model (Mullahy, 1986). However, the hurdle Poisson model would only distinguish whether or not trade between countries occurs and, given that two countries are trading, how large a volume of trade takes place. The zero-inflated model considers two different kinds of zero-valued trade flows: countries that never trade and countries that do not trade now, but potentially could trade in the future (based on the latent probability to trade according to manifest dimensions like distance, institutional proximity, etc.). Hence, a distinction can be made between pairs of countries with exactly zero probability of trade, pairs of countries with a non-zero trade probability who still happen not to be trading in a given year, and pairs of countries that are trading. As the zero-inflated model supersedes the hurdle model (Long, 1997) in that it accounts for unobserved heterogeneity in the population with a zero count, we do not further estimate or interpret the hurdle logit-Poisson model or the hurdle logit-negative binomial model here (see Linders et al., 2008, for a hurdle Poisson model of bilateral trade patterns).

On a similar note, the zero-inflated Poisson and negative binomial models bear resemblance to the Heckman selection model (Bikker and De Vos, 1992; Linders and De Groot, 2006; Helpman et al., 2008), which also corrects for the probability of trade in the gravity equation. In the Heckman selection model (Heckman, 1979), the selection equation determines whether or not bilateral trade between two countries in the sample is observed, while the regression model determines the potential size of bilateral trade. However, compared to the Heckman Selection model, the zero-inflated Poisson and negative binomial models are less restrictive, 
as they do not rely on stringent normality assumptions, nor do they require an exclusion restriction or instrument for the second stage of the equation (the regression on the volume of trade). In the Heckman selection model, as seen in the context of the gravity trade model, this instrument should reflect a variable that influences the absence of trade but is unrelated to the volume of trade. Naturally, such an instrumental variable is often hard to find. In addition, despite the fact that the Heckman selection model also provides a natural way to deal with zero counts, the bias created by the logarithmic transformation in the regression part (second stage) of the model still poses a problem. Because the modified Poisson family provides alternatives to deal with overdispersion and excess zero flows, we do not consider the Heckman log-normal specification in our comparison (see Linders and De Groot (2006) for a comparison of the Heckman selection model to other log-normal solutions to the problem of including zero flows).

\section{Empirical Example: Determinants of Bilateral Trade}

\subsection{Data and Variables}

To compare the different specifications, we focus on trade patterns for a set of 138 countries in the period 1996-2000 (UN COMTRADE database; Feenstra et al., 2005). These are all listed in Appendix A. Excluding domestic trade, there are potentially $138 \times 137=18906$ individual trade flows between the 138 countries of origin (the exporters) and the 138 countries of destination (the importers). We use averagely yearly exports expressed in millions of US dollars as an indicator of the bilateral trade volume, such that each pair of countries yields two observations, each country being both an exporter and importer. We use reported exports rather than reported imports, as the former provides a better coverage. As can be derived from Figure 1, the frequency distribution of the volume of trade across trade 
flows strongly deviates from normality (skewness=37.57, kurtosis=1906). In fact, over 50\% of all bilateral trade flows takes the value zero.

\section{INSERT FIGURE 1 ABOUT HERE}

Despite the fast growth in world trade during the past decades, barriers of physical distance, culture, institutional frameworks and economic policy still yield considerable costs to international trade (Anderson and Van Wincoop, 2004). We have included a variety of explanatory variables in the gravity equation, which affect trade patterns by increasing or decreasing the transactional distance between countries. More specifically, we distinguish between tangible and intangible trade barriers (Andersen and Van Wincoop, 2004; Linders et al., 2008). First, tangible barriers obstruct trade. These barriers are directly observable in terms of their effect on the costs or quantities of trade. Examples are transport barriers and trade policy barriers (tariffs and import and export quota). Second, we can identify intangible trade barriers, which cannot be observed directly in terms of a monetary or quantitative restriction. Intangible trade barriers include barriers of incomplete information, cultural barriers (including language and history), and institutional barriers (institutional distance) across countries (e.g., Andersen and Van Wincoop, 2004). Table 1 provides summarized

statistics of the variables included in the gravity equation. See Appendix B for a full description of these variables and their sources.

INSERT TABLE 1 ABOUT HERE 


\subsection{Empirical Results}

In this section, we include zero flows in the gravity equation using the different specifications that we distinguished above. First, we present results for the log-normal specification, estimated by OLS. We discuss a naïve extension of the log-normal model to include zero flows. After that, we move on to discuss the standard Poisson model, as a more natural way to include zero flows. Finally, we show the results for modified Poisson models that can correct for overdispersion and excess zeros.

Model 1 in Table 2 show the results of the estimation of the log-normal model, including fixed effects and using the White estimator to obtain (cluster-)robust standard errors ${ }^{\mathrm{iv}}$, in which the zero-valued flows have been omitted from the sample. Overall, it can be inferred that, in line with the trade literature, most variables have the expected sign and are highly statistically significant. The volume of trade decreases with geographical distance: an increase in distance by $1 \%$ leads to a decrease in trade by $0.84 \%$. This is consistent with the average estimate of distance decay of -0.9 found in the trade literature (Disdier and Head, 2008). The variables describing cultural and economic proximity of countries, such as common language, having ever been in a colonial relationship, and having a free trade agreement, all positively affect the volume of bilateral trade.

\section{INSERT TABLE 2 AND 3 ABOUT HERE}

Taking into account the possible bias created by the exclusion of zero-valued flows, Models 2a-2e in Table 2 show the results of the estimation of the log-normal model, including fixed effects and using the White estimator to obtain (cluster-)robust standard errors, in which the zeros in the sample have been substituted by a small positive value in order to avoid sample 
selection bias. This small positive value ranges here between 0.01 (Model 2e) to 1 (Model 2a). Compared to Model 1, in which the zero values had been excluded, the effects of the tangible and intangible barriers on the volume of bilateral trade are of the same sign, except for the effect of sectoral complementarities. However, the obtained effect sizes differ substantially between the model without zeros and the various transformed models with zeros. The choice of the positive constant that enables zero flows to be included in the lognormal specification heavily affects regression outcomes. By varying this constant $(1,0.5$, 0.1, 0.05, and 0.01) in Models 2a-2e, we find that the values of the regression coefficients greatly vary with the constant selected, as differences of $50 \%$ or more are not uncommon. Following King (1988), it indeed seems that you can generate any parameter estimate to your liking, which is typically an undesirable property of the OLS estimation of the log-normal transformed gravity model. Given that omitting the zero values gives biased results and the choice of the constant has a strong effect on the parameter values, alternative estimation techniques that avoid these problems are desirable.

Because the logarithmic transformation of the gravity model suffers from Jensen's inequality, potentially severe bias due to unobserved heterogeneity, and cannot deal with zero values in a straightforward way, alternative estimation techniques may be more appropriate. In particular, Poisson estimation enables us to move away from the need of a logarithmic transformation of the gravity model. Table 3 presents models that use Poisson and modified Poisson estimation techniques.

Specification (3) uses the Poisson pseudo maximum likelihood (PPML) estimator introduced by Santos Silva and Tenreyro (2006). The fixed-effects Poisson regression is estimated using the White estimator of variance as a first attempt to account for unobserved heterogeneity. 
From specification (3) in Table 3, it can be inferred that the parameter estimates tend to be lower compared to the OLS specifications in (1). Although the direction of the observed effects in general remains the same, the PPML estimates point out that the elasticities of common language and history are smaller than indicated by the OLS estimates. On a similar note, the border effect, the free trade agreement effect, and the sectoral complementarities effect appear to be significantly larger under PPML. The parameter of institutional distance is not significant in this model.

To control for unobserved heterogeneity and excess zeros, which may otherwise lead to biased and inefficient results, the PPML estimator was tested against the negative binomial pseudo maximum likelihood model (NBPML), the zero-inflated Poisson pseudo maximum likelihood model (ZIPPML), and the zero-inflated negative binomial pseudo maximum likelihood model (ZINBPML). The zero-inflated models generate two sets of parameter estimates: one set for the logit model, which identifies members of the group of pairs of countries always having zero values (pairs of countries that never trade), and one set for the Poisson and negative binomial parts, which predict the probability of a count belonging to the group of countries that have theoretically non-zero trade flows. As can be derived from Model 5 and 6 in Table 2, the signs of the coefficients in the logit model are usually opposite those in the Poisson and negative binomial parts. With respect to the ZIPPML model (5), we find that geographical distance, common language, and institutional distance in particular affect the probability of trade, which can be derived from the logit part of the model. If the geographical distance between countries increases by $1 \%$, the trade probability of country pairs belonging to the never-trading group increases by $1.051 \%$. Likewise, if the institutional distance between countries increases by $1 \%$, the trade probability of countries belonging to

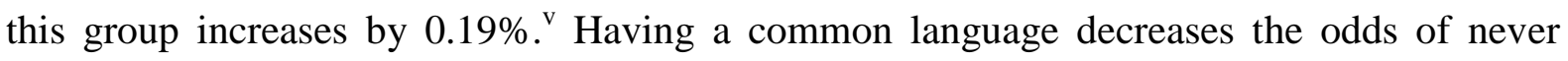


trading by $73 \%$. Although common language and institutional distance both affect the trade probability according to the ZIPPML outcomes, these variables were not found to have an effect on the expected volume of trade. Looking at the Poisson part of the model, it appears that in particular physical distance, having a common border, a common history, free trade agreements, and being specialized in different economic sectors increase the expected volume of trade when holding all other variables constant. Hence, it can be inferred from the ZIPPML outcomes that whether and to what extent countries trade are related to different factors.

The ZINBPML model can be interpreted in a similar fashion. Compared to the PPML estimator, the regression coefficients estimated by ZIPPML in the Poisson part of the model are similar, while the regression coefficients estimated by NBPML and ZINBPML differ substantially from the effects under PPML. More specifically, the effects of geographical distance, common language, and common history are substantially larger under NBPML and ZINBPML, while the effects of free trade agreements are substantially smaller. Surprisingly, there is even a negative effect of having a free trade agreement on the expected volume of trade under NBPML. In addition, the parameter estimates generated by NBPML and ZINBPML deviate more from the OLS coefficients than the estimates generated by PPML and ZIPPML.

\subsection{Model Comparison among OLS, Poisson and Modified Poisson Estimations}

After comparing the effect size estimates between OLS, Poisson and modified Poisson estimators, we want to assess the choice of correct model specification explicitly. The comparative performance of the OLS, Poisson and modified Poisson specifications can be assessed on the basis of different measures of goodness-of-fit (see Long, 1997). As the use of 
the log-normal specification can be refuted on theoretical grounds, and as the available goodness-of-fit statistics to compare the OLS with the Poisson and modified Poisson specifications are rather limited, we predominantly focus on the comparison between the Poisson and modified Poisson estimations. The correct model choice within the Poisson family of estimators also depends on the extent to which overdispersion and excess zeros are empirically relevant.

Probably the most popular way to compare the goodness-of-fit of different models is by comparing the estimated and observed values of the dependent variable (e.g., Bergkvist and Westin, 1998; Martinez-Zarozo et al., 2007). Figures 2A and 2B show the residuals (the observed minus the estimated volume of trade) against the observed volume of trade. From Figure 2A, it is clear that the NBPML and ZINBPML perform the worst in terms of out-ofsample forecast. In particular, the NBPML and ZINBPML estimators tend to overpredict the volume of medium and large trade flows. On the contrary, PPML and ZIPPML perform relatively well, as the estimated volume of trade does not deviate much from the observed volume of trade for neither small nor large trade flows. In this respect, PPML and ZIPPML do not only outperform NBPML and ZINBPML, but also OLS (see Figure 2B). In particular, OLS tends to underpredict large trade flows.

\section{INSERT FIGURE 2A AND 2B ABOUT HERE}

The good performance of PPML and ZIPPML based on the comparison between the linearly predicted volume of trade and the observed volume of trade is also reflected in the Stavins and Jaffe Goodness-of-Fit statistic (Stavins and Jaffe, 1990; see also Martinez-Zarozo et al., 2007). The Stavins and Jaffe goodness-of-fit statistics are based on the Theil inequality 
coefficient (Theil's U), which usually ranges from 0 to 1 (Theil, 1958). If the forecast is perfect, the Stavins and Jaffe statistic takes on the value 1. As can be derived from Tables 2 and 3, the value of the Stavins and Jaffe goodness-of-fit statistic obtained from the PPML and ZIPPML models is significantly higher than the values obtained from the NBPML and ZINBPML models. Moreover, the Stavins and Jaffe statistic is higher for PPML and ZIPPML than for all (truncated) OLS estimations. This would indeed confirm that the PPML and ZIPPML models provide a more accurate forecast. This is contrary to the findings of Martinez-Zarzoso et al. (2007), who find that the out-of-sample forecasts for OLS (estimated by taking the natural exponent of the predicted value) generally outperform the out-of-sample forecasts for PPML. However, results may of course vary across data sets, and more research is definitely needed on this topic.

A drawback of comparing the goodness-of-fit on the basis of observed versus estimated values is that this 'measure of goodness-of-fit solely based upon the expected value is unable to address the improvement achieved by a model with less restrictive variance assumptions' (Liu and Cela, 2008: 4). The modified Poisson models such as the NBPML, ZIPPML and ZINBPML have the advantage of imposing fewer restrictions on variance and allowing more heterogeneity. We are also interested in these aspects for the choice of specification. In particular, we argued that overdispersion and excess zeros are probably relevant in the context of bilateral trade flows. An alternative way to take this into account and compare model fit of the different Poisson and modified Poisson models is to examine the probability distribution and compare the expected probabilities to the observed probabilities for each specification. Figure 3 shows these for PPML, NBPML, ZIPPML, and ZINBPML for all observed bilateral trade between 0 and 20 million (about $75 \%$ of the sample). The points above the $\mathrm{x}$-axis represent an overprediction of the probability of observing that volume of 
trade, while the points below the $\mathrm{x}$-axis represent an underprediction. From Figure 3, it becomes clear that ZINBPML performs the best, followed by NBPML and ZIPPML, which do about equally well. Moreover, the ZINBPML and ZIPPML specifications predict most accurately the number of zero-valued trade flows in the data set. PPML in particular tend to overpredict low volumes of trade.

\section{INSERT FIGURE 3 ABOUT HERE}

Examining more formal statistics concerned with comparing the observed and predicted distributions (see Table 3), the likelihood ratio test of overdispersion ( $\alpha$ ) and the Vuong test indicate that (1) NBPML is favored over PPML, (2) ZIPPML is favored over PPML, and (3) ZINBPML is favored over NBPML, ZIPPML and PPML. Neither the Vuong nor the likelihood ratio test of overdispersion $(\alpha)$ can be used to compare NBPML and ZIPPML. However, both the Akaike Information Criterion (AIC) and the Bayesian Information Criterion (BIC) indicate that the NBPML should be preferred over the ZIPPML. Although AIC and BIC can also be obtained for the OLS models, these values do not directly compare with values of the AIC and BIC in the Poisson and modified Poisson models, as OLS uses a different dependent variable (the natural logarithm of the volume of trade instead of the volume of trade itself).

To summarize, the different goodness-fit statistics do not all point to the same conclusion. On the one hand, PPML and ZIPPML perform the best when comparing the expected and observed values of the dependent variable. They even outperform OLS in our example. On the other hand, NBPML and ZINBPML perform the best when comparing the expected and observed probabilities, thereby taking into account the model improvement by introducing 
less restrictive variance assumptions (Liu and Cela, 2008). Overall, it can be inferred that ZIPPML performs the best on average, as rated by both criteria. It has a reasonable fit of estimated trade, can include zero flows, and accounts for different types of zero flows, correcting for excess zeros and the overdispersion that results from that.

\section{Discussion and Conclusion}

The renewed and extended interest in the correct econometric specification of the gravity model of trade fosters the discussion on the estimation techniques applied (Santos Silva and Tenreyro, 2006; Martinez-Zarzoso et al., 2007). Three problems often encountered when analyzing bilateral trade data using the conventional log-normal specification of the gravity model of trade are (1) the bias created by the logarithmic transformation (Jensen's inequality), (2) the failure of the homoscedasticity assumption, and (3) the way zero-valued trade flows are treated. These problems normally result in biased and inefficient estimates.

To overcome these problems, this paper considers Poisson and modified Poisson fixed-effects estimations (negative binomial, zero-inflated), extending the empirical model put forward by Santos Silva and Tenreyro (2006). This class of models is hypothesized to be a viable alternative to its log-normal counterpart, both from a theoretical and empirical point of view. In contrast to the log-normal specification, these specifications of the gravity model do not bring about the problems mentioned. First, the linking function is log-linear instead of loglog. Hence, the Poisson and modified Poisson regression models avoid underpredicting large trade flows or the total volume of trade. Second, the Poisson and modified Poisson regression estimates are consistent in the presence of heteroskedasticity and reasonably efficient, especially for large samples. Third, because of its multiplicative form, the Poisson and modified Poisson specifications provide a natural way to deal with zero-valued trade flows. 
Particularly, the zero-inflated model theoretically considers two different kinds of zerovalued trade flows: countries that never trade and countries that do not trade now but potentially could, based on the latent trade probability determined by manifest dimensions like geographical separation, institutional proximity, etc.).

Empirically, we compare OLS estimates (leaving the zero-valued flows out or replacing them by a small constant) with Poisson and modified Poisson models using the same trade data between countries (UN COMTRADE data with more than $50 \%$ of bilateral relations showing no trade). Using these models yields mixed results regarding the tangible and intangible trade barriers. In line with the trade literature, most variables have the expected sign and are highly statistically significant. The volume of trade decreases with geographical distance. The variables describing cultural and economic proximity of countries, such as common language, having ever been in a colonial relationship, and having a free trade agreement, all positively affect the volume of bilateral trade. Also, more traditional explanations of trade patterns, such as tangible policy barriers (embodied by an FTA variable and bilateral import tariffs), comparative advantages, and factor proportion differences, are important for explaining trade patterns.

The magnitudes of many coefficients differ considerably in the various specifications applied. Our analyses confirm that leaving out the zero-valued flows leads to seriously biased results, as the omitted zeros are non-randomly distributed across the importing and exporting countries. Moreover, in OLS models in which the zero-valued flows have been replaced by a small constant, we find that the values of the regression coefficients greatly vary with the value of the constant selected. 
We show that the Poisson and modified Poisson (negative binomial, zero-inflated) modeling techniques applied may provide a viable alternative to the log-normal specification of the gravity trade model. From a theoretical point of view, these specifications of the gravity model do not bring about the problems of the log-normal formalism, and zero-inflated models allow for the possibility to detach the trade probability from the trade volume.

To further motivate the choice of econometric specification, we compare the model fit of the different specifications. The different goodness-of-fit statistics applied to the gravity models do not all lead to the same conclusion, though. On the one hand, the Poisson model (PPML) and the zero-inflated Poisson model (ZIPPML) perform the best when comparing the estimated and observed values of the dependent variable, and even outperform OLS in our example. On the other hand, the negative binominal model (NBPML) and the zero-inflated negative binominal model (ZINBPML) perform better when comparing the expected and observed probabilities, which takes into account the model improvement by introducing less restrictive variance assumptions. If we consider model fit and the relevance of excess zeros, the zero-inflated Poisson model (ZIPPML) on average scores best. Zero-inflated models, furthermore, allow for the possibility to detach the probability to trade from the volume of trade. This implies that we get additional information on the determinants of the probability of different types of zero flows. Zero-inflated estimation controls the parameters in the flow part of the gravity model for sample selection effects. Still, further investigation is needed to more robustly compare the forecast accuracy of these models and to value the trade-offs and criteria on which the models should be optimally evaluated. 


\section{Acknowledgement}

We thank an anonymous reviewer and participants of the Workshop on Spatial Economics and Trade in Glasgow for useful suggestions and comments on earlier versions of this paper. All errors remain ours.

\section{References}

Andersen, J.E. and E. van Wincoop (2003) Gravity with Gravitas: a solution to the border puzzle, American Economic Review, 93, 170-92.

Andersen, J.E. and E. van Wincoop (2004) Trade costs, Journal of Economic Literature, 17, 691-751.

Bergkvist, E. and L. Westin (1998) Estimation of gravity models by OLS estimation, NLS estimation, Poisson and neural network specifications, Cerum Working Paper, 6, Umea Universitet.

Bikker, J.A. and A.F. de Vos (1992) An international trade flow model with zero observations: an extension of the Tobit model, Cahiers Economiques de Bruxelles, 379404.

Black, W.R. (1992) Network autocorrelation in transport network and flow systems, Geographical Analysis, 24, 207-222.

Bohara, A.K. and R.G. Krieg (1996) A zero-inflated Poisson model of migration frequency, International Regional Science Review, 19, 211-22.

Bröcker, J. (1989) Partial equilibrium theory of interregional trade and the gravity model, Papers of the Regional Science Association, 66, 7-18.

Bröcker, J. and H.C. Rohweder (1990) Barriers to international trade: methods of measurement and empirical evidence, The Annals of Regional Science, 24, 289-305. 
Cameron, A.C. and P.K. Trivedi (1986) Econometric models based on count data: comparisons and applications of some estimators and tests, Journal of Applied Econometrics, 1, 29-53.

De Groot, H.L.F., G.J.M. Linders, P. Rietveld, and U. Subramanian (2004) The institutional determinants of bilateral trade patterns, Kyklos, 57, 103-23.

Disdier, A.C. and K. Head (2008) The puzzling persistence of the distance effect on bilateral trade, Review of Economics and Statistics, 90, 37-41.

Eaton, J. and S. Kortum (2002) Technology, geography and trade, Econometrica, 70, 174179.

Eichengreen, B. and D.A. Irwin (1998) The role of history in bilateral trade flows, in (ed.), The Regionalization of the World Economy (Ed.) J.A. Frankel, University of Chicago Press, Chicago, 33-57.

Egger, P. (2005) Alternative techniques for the estimation of cross-section gravity models, Review of International Economics, 13, 881-91.

Feenstra, R.C. (2004) Advanced International Trade: Theory and Evidence, Princeton University Press, Princeton.

Feenstra, R.C., R.E. Lipsey, H. Deng, A.C. Ma and H. Mo (2005) World trade flows 19622000, NBER Working Paper 11040, Cambridge, MA: National Bureau of Economic Research.

Flowerdew, R. and M. Aitkin (1982) A method of fitting the gravity model based on the Poisson distribution, Journal of Regional Science, 22, 191-202.

Fotheringham, A.S. and M.E. O'Kelly (1989) Spatial Interaction Models: Formulations and Applications, Kluwer, Dordrecht.

Frankel, J.A. (1997) Regional Trading Blocs in the World Economic System, Institute for International Economics, Washington DC. 
Ghazalian, P., L. Tamini, B. Larue and J.P. Gervais (2007) A gravity approach to evaluate the signficance of trade liberalization in vertically-related goods in the presence of non-tariff barriers, MPRA Paper 2744, Laval University.

Gourieroux, C., A. Montfort and A. Trognon (1984) Pseudo maximum likelihood methods: applications to Poisson models, Econometrica, 52, 701-20.

Greene, W.H. (1994) Accounting for excess zeros and sample selection in Poisson and negative binomial models, Stern School of Business, New York University, Working Paper 94-10.

Haveman, J. and D. Hummels (2004) Alternative hypotheses and the volume of trade: the gravity equation and the extent of specialization, Canadian Journal of Economics, 37, 199218.

Haworth, J.M. and P.J. Vincent (1979) The stochastic disturbance specification and its implications for log-linear regression, Environment and Planning A, 11, 781-90.

Heckman, J.J. (1979) Sample selection bias as a specification error, Econometrica, 47, 15361.

Helpman, E., M. Melitz and Y. Rubinstein (2008) Estimating trade flows: trading partners and trading volumes, Quarterly Journal of Economics, 123, 441-87.

Johnson, N. and S. Kotz (1969) Distributions in Statistics - Discrete Distributions, John Wiley and Sons, New York.

Isard, W. (1954) Location theory and trade theory: short run analysis, Quarterly Journal of Economics, 68, 305-22.

King, G. (1988) Statistical models for political science event counts: bias in conventional procedures and evidence for the exponential Poisson regression model, American Journal of Political Science, 32, 838-63. 
Lambert, D. (1992) Zero-inflated Poisson regression with an application to defects in manufacturing, Technometrics, 34, 1-14.

Linders, G.J.M. and H.F.L. de Groot (2006) Estimation of the gravity Equation in the Presence of Zero Flows, Tinbergen Institute Discussion Paper, 2006-072/3.

Linders, G.J.M., M.J. Burger and F.G. van Oort (2008) A rather empty world: the many faces of distances and the persistent resistance to international trade, Cambridge Journal of Regions, Economy and Society, 1, 439-458.

Liu, W.S. and J. Cela (2008) Count data models in SAS. SAS 2008 Global Forum, Paper 371-2008.

Long, J.S. (1997) Regression Models for Categorical and Limited Dependent Variables, Sage, Thousand Oaks.

Loungani, P., A. Mody and A. Razin (2002) The global disconnect: the role of transactional distance and scale economies in gravity equations, Scottish Journal of Political Economy, $49,526-43$.

Lovett, A. and R. Flowerdew (1989) Analysis of count data using Poisson regression, Professional Geographer, 41, 190-98.

Martinez-Zarzoso, I., D. Nowak-Lehman and S. Vollmer (2007) The log of gravity revisited, CeGE Discussion Paper 64, University of Gottingen.

Matyas, L. (1998) The gravity model: some econometric considerations, The World Economy, 21, 397-401.

Mullahy, J. (1986) Specification and testing of some modified count models, Journal of Econometrics, 33, 341-65.

Overman, H., S. Redding and T. Venables (2003) The economic geography of trade, production, and income: a survey of the empirics, in The Handbook of International Trade (Eds) J. Harrigan and K. Choi, Blackwell Publishers, London, 353-87. 
Rauch, J.E. (1999) Networks versus markets in international trade, Journal of International Economics, 48, 7-35.

Santos Silva, J.C.M. and S. Tenreyro (2006) The log of gravity, The Review of Economics and Statistics, 88, 641-58.

Senior, M.L. (1979) From gravity modelling to entropy maximizing, Progress in Human Geography, 3, 175-210.

Stavins, R.N. and A.B. Jaffe (1990) Unintended impacts of public investments on private decisions: the depletion of forested wetlands, American Economic Review, 80, 337-52.

Theil, H. (1958) Economic Forecasts and Policy, North Holland, Amsterdam.

Tinbergen, J. (1962) Shaping the World Economy The Twentieth Century Fund, New York.

Ullman, E.L. (1954), Geography as spatial interaction, in Interregional Linkages, Proceedings of the Western Committee on Regional Economic Analysis (Eds) D. Rezvan and E.S. Engelbert, UCLA, Berkeley, CA, 63-71.

Vuong, Q.H. (1989), Likelihood ratio tests for model selection and non-nested hypotheses, Econometrica, 57, 307-33.

Woolridge, J.M. (2002), Econometric Analysis of Cross Section and Panel Data, MIT Press, Boston. 
Table 1: Statistics of Variables used in the Gravity Equation

\begin{tabular}{|l|c|c|c|c|c|}
\hline & Mean & Std. Dev. & Min. & Max & N \\
\hline $\begin{array}{l}\text { Yearly average volume of } \\
\text { trade (1996-2000) }\end{array}$ & 270.1 & 2884 & 0 & 189000 & 18906 \\
\hline Geographical distance (ln) & 8.685 & 0.800 & 4.007 & 9.897 & 18906 \\
\hline Contiguity dummy & 0.012 & 0.140 & 0 & 1 & 18906 \\
\hline Common language dummy & 0.132 & 0.339 & 0 & 1 & 18906 \\
\hline Common history dummy & 0.023 & 0.151 & 0 & 1 & 18906 \\
\hline Free trade agreement dummy & 0.054 & 0.226 & 0 & 1 & 18906 \\
\hline Institutional distance & 2.014 & 1.931 & 0.002 & 11.14 & 18906 \\
\hline Sectoral complementarities & 2.000 & 1.590 & 0.004 & 15.71 & 18906 \\
\hline
\end{tabular}


Table 2: OLS and Average Yearly Trade from 1996-2000

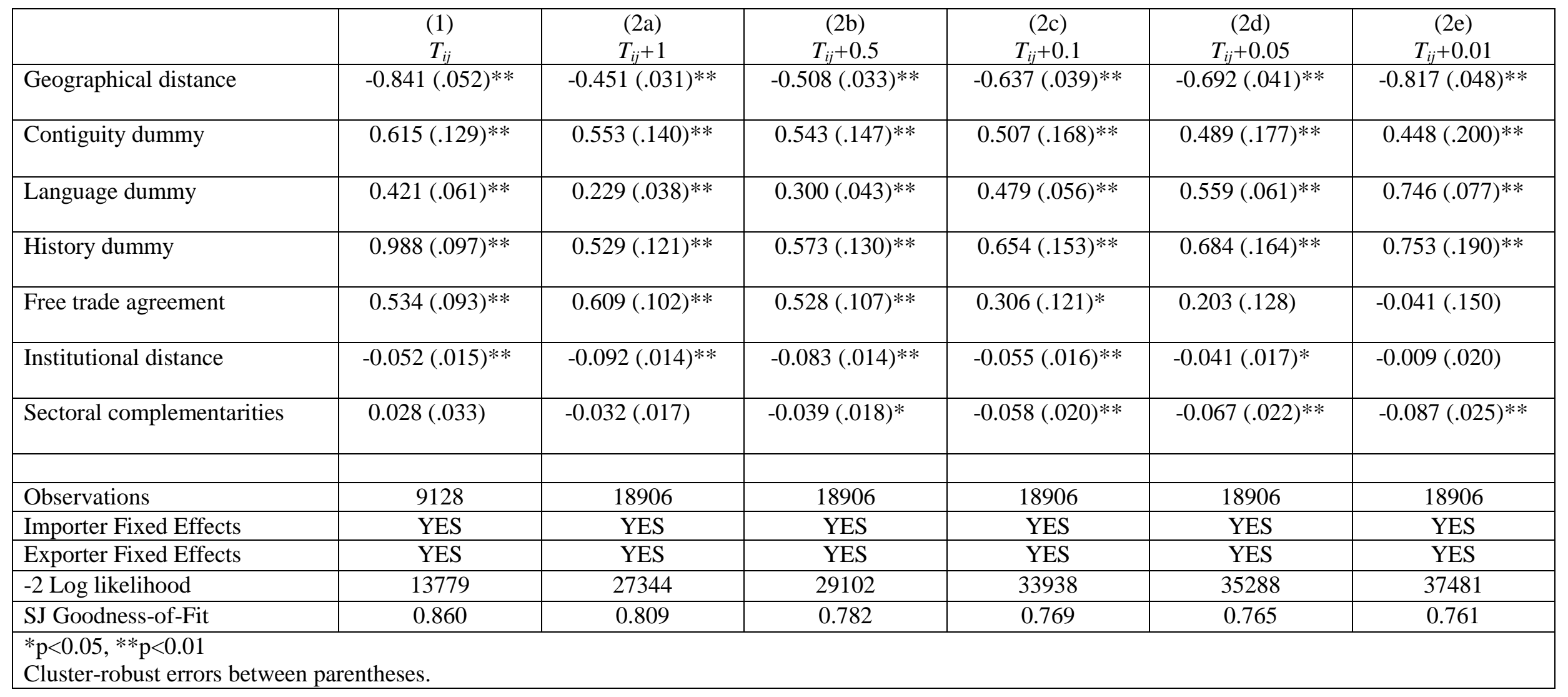


Table 3 Poisson and Modified Poisson PML on Average Yearly Trade from 1996-2000.

\begin{tabular}{|c|c|c|c|c|c|c|}
\hline & $\begin{array}{c}\text { PPML (3) } \\
T_{i j}\end{array}$ & $\begin{array}{l}\text { NBPML (4) } \\
T_{i j}\end{array}$ & \multicolumn{2}{|c|}{ Zero-Inflated PPML (5) } & \multicolumn{2}{|c|}{$\begin{array}{c}\text { Zero-Inflated NBPML (6) } \\
T_{i j}\end{array}$} \\
\hline Geographical distance & $-0.556(.042)^{* *}$ & $-1.058(.061)^{* *}$ & $1.051(.098)^{* *}$ & $-0.549(.042)^{* *}$ & $0.663(.123)^{* *}$ & $-0.989(.060)^{* *}$ \\
\hline Language dummy & $0.109(.072)$ & $0.741(.102)^{* *}$ & $-1.312(.135)^{* *}$ & $0.099(.072)$ & $-0.160(.227)^{* *}$ & $0.424(.078)^{* * *}$ \\
\hline Free trade agreement & $0.548(.075)^{* *}$ & $-0.036(.129)$ & $-0.090(.262)$ & $0.568(.076)^{* *}$ & $0.360(.329)$ & $0.398(.101)^{* * *}$ \\
\hline Institutional distance & $0.001(.020)$ & $-0.043(.021)^{*}$ & $0.088(.034)^{* *}$ & $-0.012(.021)$ & $-0.026(.024)$ & $-0.038(.016)^{*}$ \\
\hline Sectoral complementarities & $0.164(.043)^{* *}$ & $-0.007(.040)$ & $0.044(.053)$ & $0.170(.043)^{* *}$ & $0.069(.099)$ & $0.002(.045)$ \\
\hline Observations & 18906 & 18906 & \multicolumn{2}{|c|}{18906} & 18906 & 18906 \\
\hline Vuong $(z)$ & & & \multicolumn{2}{|c|}{$12.98^{* *}$} & \multicolumn{2}{|c|}{$19.36^{* *}$} \\
\hline AIC & 1696788 & 99334 & \multicolumn{2}{|c|}{1616401} & \multicolumn{2}{|c|}{$\frac{96239}{99644}$} \\
\hline BIC & 1699001 & 101554 & \multicolumn{2}{|c|}{1620827} & & \\
\hline S\&J Goodness-of-Fit & 0.887 & 0.052 & \multicolumn{2}{|c|}{0.886} & \multicolumn{2}{|c|}{0.563} \\
\hline
\end{tabular}


Distribution of Trade Volume (in millions of year 2000-dollars)

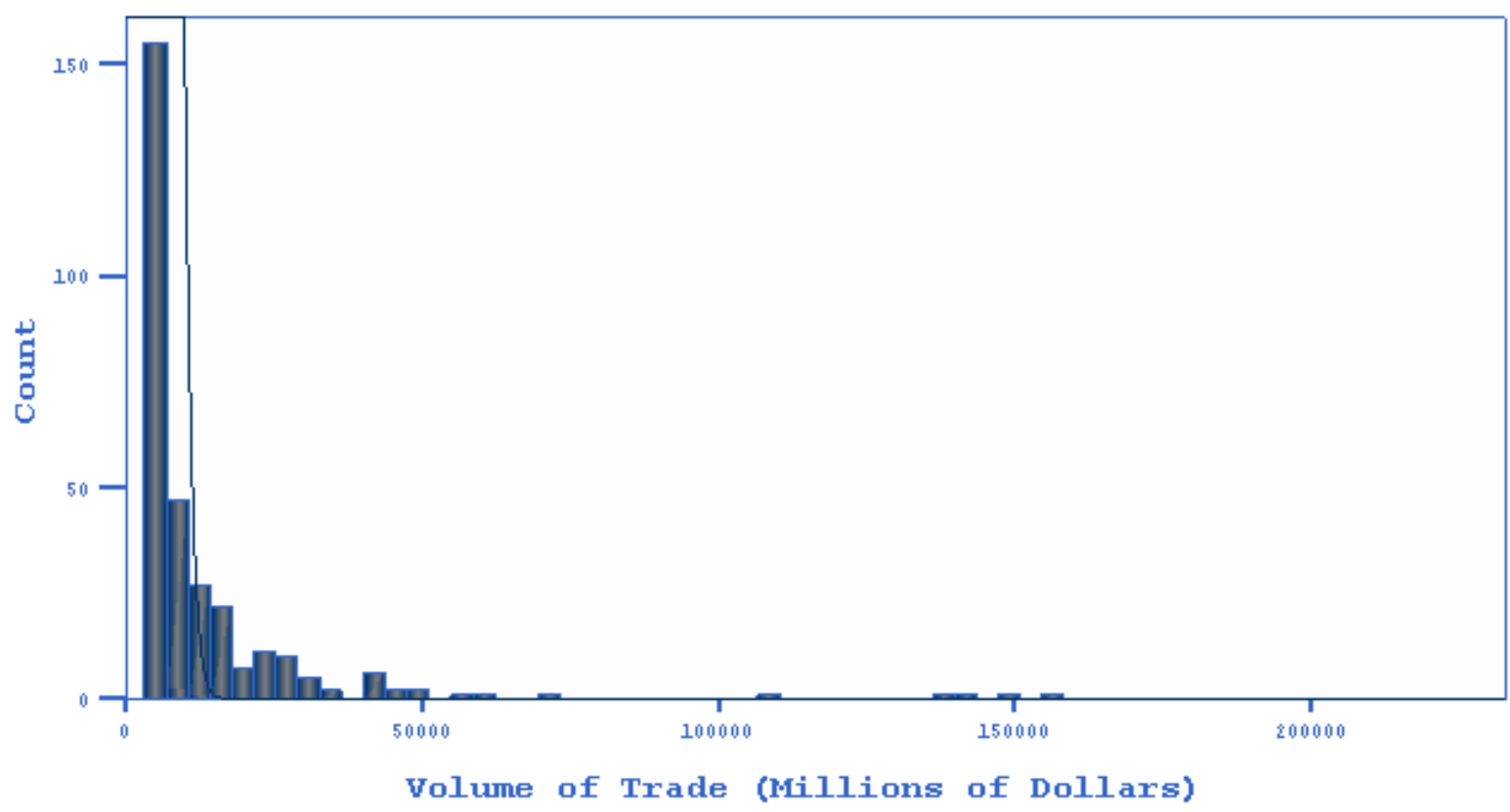


Figure 2A: Comparison of the Estimated Trade Volume and the Observed Trade Volume of Trade by Specification
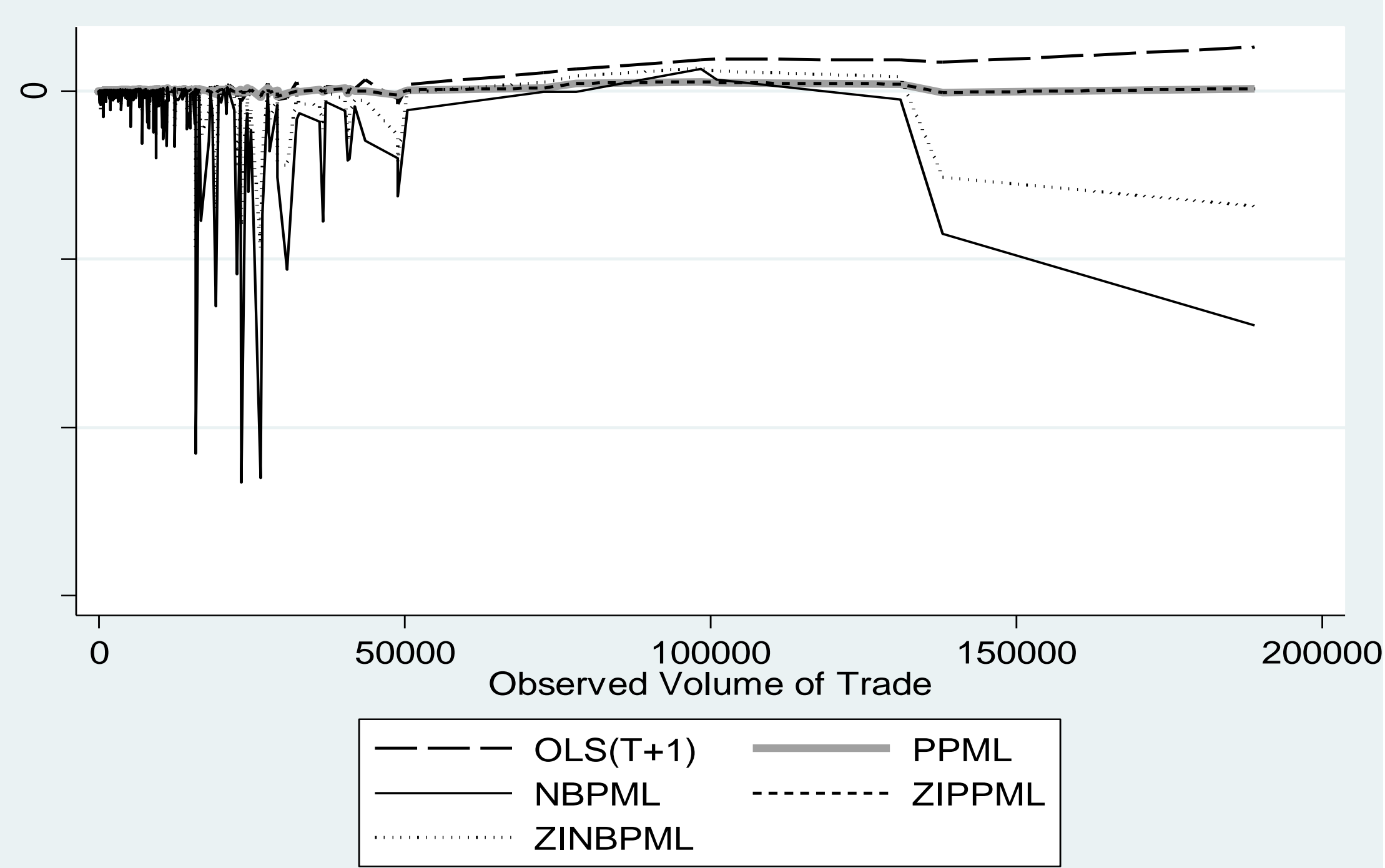
Figure 2B: Comparison of Estimated Trade Volume and Observed Trade Volume by Specification

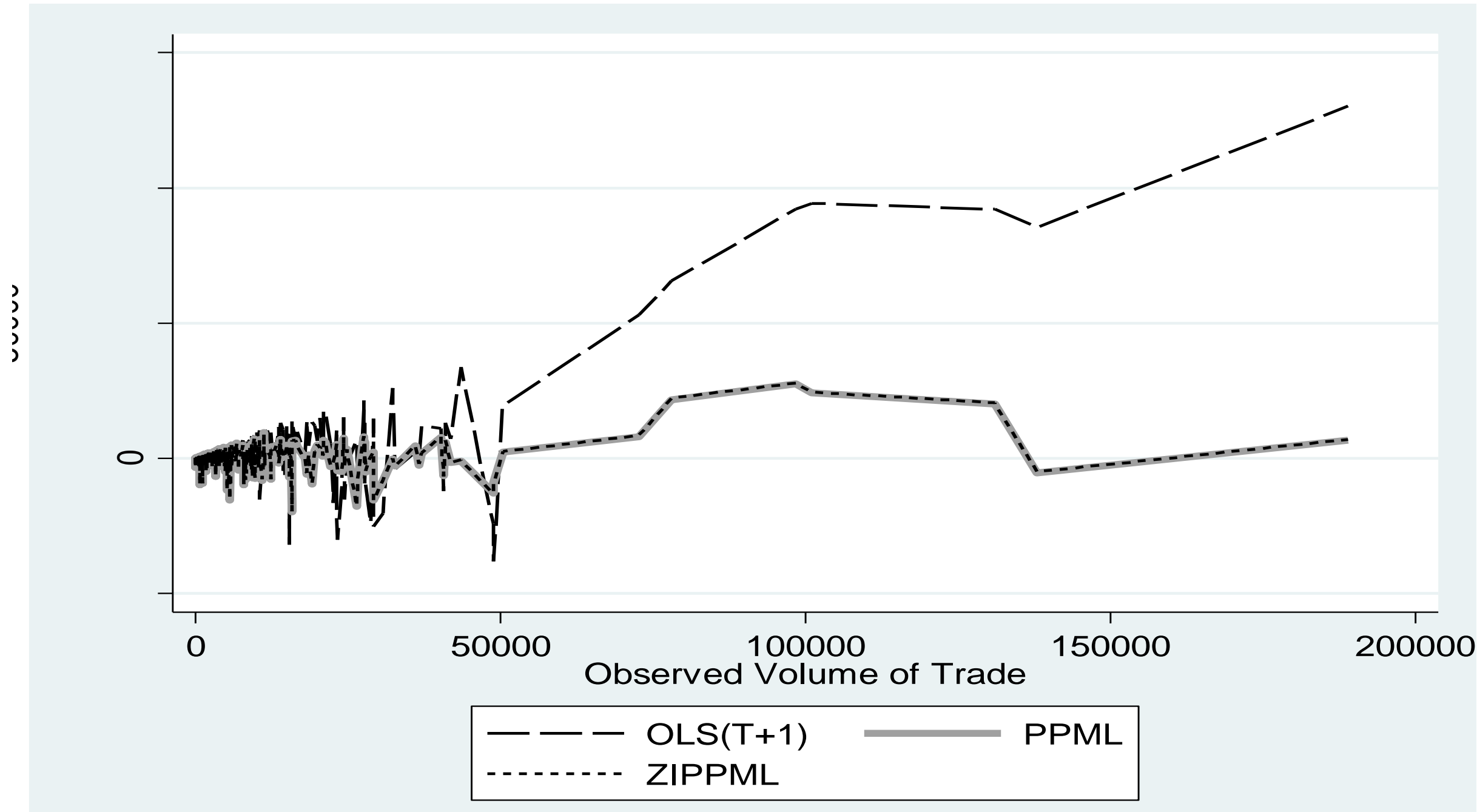


Figure 3: Observed versus Estimated Probability of the Volume of Trade

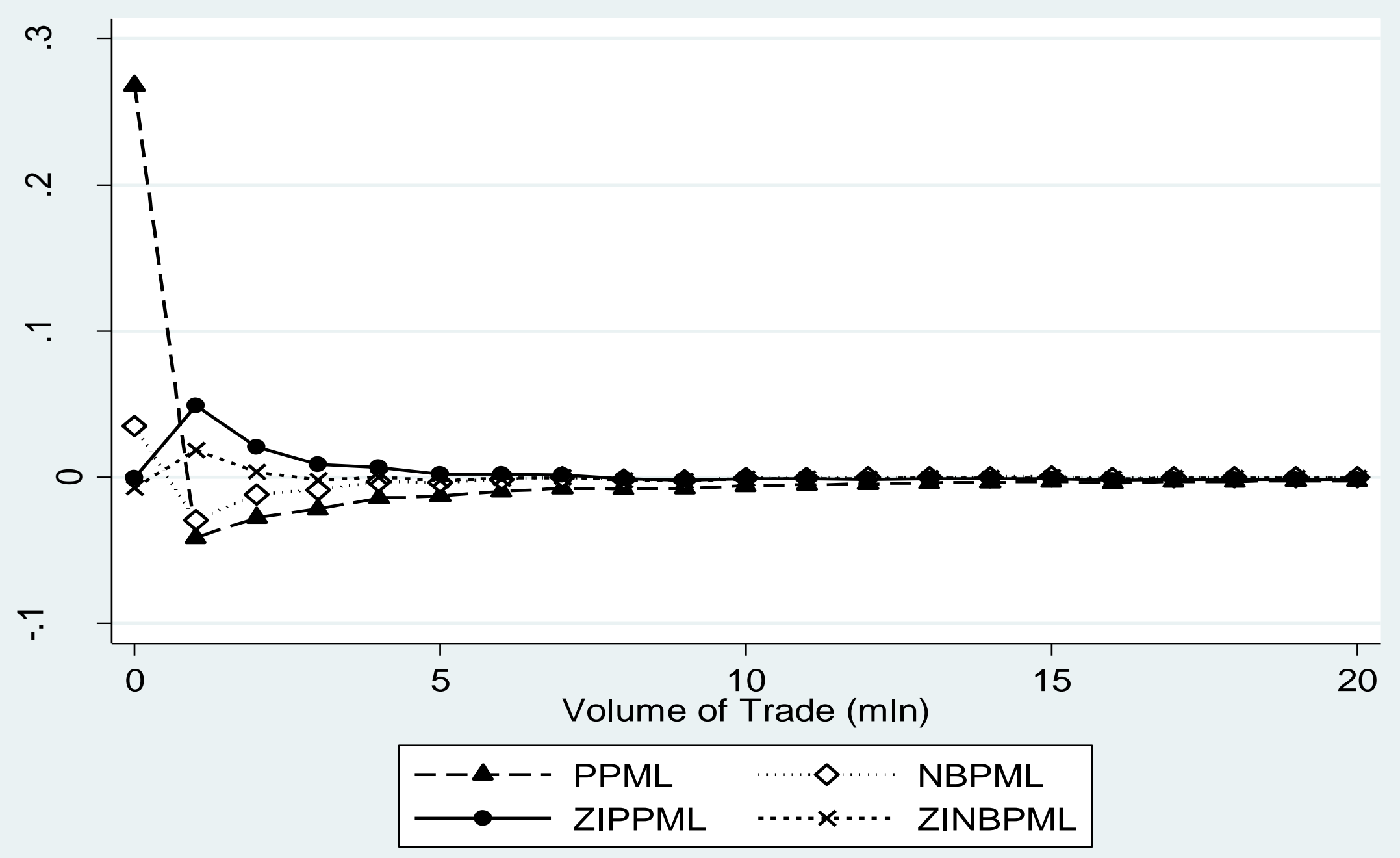




\section{Appendix A: Countries included}

\begin{tabular}{|c|c|c|}
\hline Albania & Gabon & Norway \\
\hline Algeria & Gambia & Oman \\
\hline Angola & Germany & Pakistan \\
\hline Argentina & Ghana & Panama \\
\hline Australia & Greece & Papua New Guinea \\
\hline Austria & Guatemala & Paraguay \\
\hline Azerbaijan & Guinea & Peru \\
\hline Bahamas & Haiti & Philippines \\
\hline Bahrain & Honduras & Poland \\
\hline Bangladesh & Hungary & Portugal \\
\hline Barbados & India & Qatar \\
\hline Belarus & Indonesia & Republic Moldova \\
\hline Belgium-Luxembourg & Iran & Romania \\
\hline Belize & Ireland & Russian Fed \\
\hline Bermuda & Israel & Rwanda \\
\hline Bolivia & Italy & Saudi Arabia \\
\hline Bosnia Herzegovina & Jamaica & Senegal \\
\hline Brazil & Japan & Singapore \\
\hline Bulgaria & Jordan & Slovakia \\
\hline Burkina Faso & Kazakhstan & Slovenia \\
\hline Burundi & Kenya & South Africa \\
\hline Cameroon & Korea Rep. & Spain \\
\hline Canada & Kuwait & Sri Lanka \\
\hline Central African Republic & Laos & Sudan \\
\hline Chad & Latvia & Suriname \\
\hline Chile & Lebanon & Sweden \\
\hline China & Libya & Switzerland-Liechtenstein \\
\hline Colombia & Lithuania & Syria \\
\hline Congo & Macau & Tanzania \\
\hline Costa Rica & Madagascar & Thailand \\
\hline Cote D'Ivoire & Malawi & Togo \\
\hline Croatia & Malaysia & Trinidad and Tobago \\
\hline Cuba & Mali & Tunisia \\
\hline Cyprus & Malta & Turkey \\
\hline Czech Rep & Mauritania & Uganda \\
\hline Denmark & Mauritius & Ukraine \\
\hline Djibouti & Mexico & United Kingdom \\
\hline Dominican Republic & Morocco & United Arabian Emirates \\
\hline Ecuador & Mozambique & Uruguay \\
\hline Egypt & Netherlands Antilles \& Aruba & USA \\
\hline El Salvador & Netherlands & Uzbekistan \\
\hline Estonia & New Caledonia & Venezuela \\
\hline Ethiopia & New Zealand & Vietnam \\
\hline Fiji & Nicaragua & Yugoslavia \\
\hline Finland & Niger & Zambia \\
\hline France-Monaco & Nigeria & Zimbabwe \\
\hline
\end{tabular}




\section{Appendix B: Data}

To compare the ability of the traditional OLS specification with that of the Poisson and modified Poisson estimation methods when dealing with zero-valued flows, we focus on trade patterns in 2000 for a set of 138 countries, all listed in Appendix A. In the analysis, we use both country-specific and bilateral data from various sources. The GDPs of the exporting and importing countries are examples of country-specific variables, while geographic distance, adjacency, and common language, among others, are examples of bilateral characteristics for each pair of countries. In this appendix, a more detailed description of the data and sources used can be found.

\section{Dependent variable}

- The yearly average volume of trade between countries (1996-2000) in millions of dollars was obtained from the UN COMTRADE database. We use bilateral exports as dependent variables, such that each country pair yields two observations, with each country being both an exporter and an importer.

\section{Independent variables: bilateral data}

The bilateral variables in a gravity equation merely reflect the distance between two countries. These variables do not necessarily reflect the geographical distance or adjacency but can also be economic (free trade area) and cultural in character (common language and history).

- In line with previous research, geographic distance is measured as the straight distance between countries ('as the crow flies'), using the capital of each country as its centre of gravity. This implies that the distance between the two centers of gravity of neighboring countries is likely to overestimate the average distance of trade between them.

- The Boolean border dummy variable takes the value of one if two countries are adjacent. Adjacency requires either a land border or a small body of water separating the two countries. Both measurement error in the distance variable and the effect of historical relations between adjacent countries are captured by this dummy variable.

- To assess whether two countries have the same official language, we use a database collected by Haveman that distinguishes fourteen languages. This data has been expanded using CIA's World Factbook to cover more countries and languages. A Boolean language dummy variable reflects whether or not two countries have a common language.

- The Boolean history dummy variable takes the value of one if the two countries had, or have, a colonial relationship, or if they were ever part of the same country. This variable is constructed on the basis of CEPII data.

- Whether pairs of countries take part in a common regional integration agreement has been determined on the basis of OECD data on major regional integration agreements. A Boolean dummy variable (FTA) indicates whether or not the importing and exporting country are both members of the same free trade area.

- Our measure of institutional distance is based on Kaufmann's six dimensions of governance quality (Kaufmann et al., 2004). These dimensions include voice and accountability, political stability, effectiveness of government, quality of regulation, rule of law, and control of corruption. All these indicators are constructed on the basis of factor analysis and reflect different aspects of the quality of governance. A more detailed description of these dimensions can be found in Kaufmann et al. (2004). We measure the institutional distance between pairs of countries by using the index developed by Kogut and Singh (1988): 
$I D_{i j}=\frac{1}{6} \sum_{k=1}^{6} \frac{\left(I_{k i}-I_{k j}\right)^{2}}{V_{k}}$,

where $I_{k i}$ indicates the $i^{\text {th }}$ country score on the $k^{\text {th }}$ dimension, and $V_{k}$ is the variance of this dimension across all countries. Institutional distance reflects the fact that a higher difference in institutional effectiveness raises adjustment costs and may decrease bilateral trust (De Groot et al., 2004). ${ }^{1}$ Traders from countries with very different levels of guaranteed property rights and the enforceability of contracts are frequently unfamiliar with the other country's formal or informal procedures for doing business.

- To more precisely capture the theory of trade concerned with the traditional factor proportions, we also include differences in production structure in our model, which we label sectoral complementarities. These are estimated much like the institutional distance is, but with the Kogut-Singh index (equation 3) estimated using the share differences from six broad sectors in the total economy of countries $i$ and $j$ (agriculture, manufacturing, construction, wholesale, transport and services). Information on the production structure of the countries used in the sample was obtained from the UNCTAD database.

${ }^{i}$ See Anderson and Van Wincoop (2004) and Feenstra (2004) for the theoretical rationale behind the gravity model of trade.

ii A similar point was motivated by econometric theory by, for example, Matyas (1998) and Egger (2005).

iii An early exception to the use of the log-normal specification is Bröcker and Rohweder (1990), who found a creative solution to reconcile trade flows with count data models, and used a Poisson estimator.

${ }^{\text {iv }}$ Here we assume that the unobserved variation is not independent across trade links and that observations are clustered within countries of origin (see also Black (1992) on spatial network autocorrelation). Similar results were obtained by clustering by countries of destination.

${ }^{v}$ Institutional distance enters the link function of the Poisson model (i.e., the gravity equation for conditional expected trade) linearly, not log-linearly. We compute an average effect of varying institutional distance from its mean by using the sample standard deviation given in Table 1 . The effect on the probability of zero trade becomes: $\mathrm{e}^{0.088^{* 1.931}}-1=0.19 \%$

\footnotetext{
${ }^{1}$ Though conceptually helpful for highlighting the importance of less tangible dimensions of trade barriers, it is sometimes hard to separate tangible and intangible barriers empirically. Institutional barriers are identified as intangible trade barriers, although in principle some of the costs related to institutions are directly observable (for example, legal costs). Most of the transaction costs related to institutions are not directly observable in the market, such as contracting costs, monitoring costs, regulatory costs, expropriation risks and other uncertainties, and adjustment costs related to differences in the quality of the institutional settings.
} 


\section{Publications in the ERIM Report Series Research* in Management}

\section{ERIM Research Program: "Organizing for Performance"}

2009

On the Specification of the Gravity Model of Trade: Zeros, Excess Zeros and Zero-Inflated Estimation Martijn J. Burger, Frank G. van Oort, and Gert-Jan M. Linders ERS-2009-003-ORG

http://hdl.handle.net/1765/14614

* A complete overview of the ERIM Report Series Research in Management: https://ep.eur.nl/handle/1765/1

ERIM Research Programs:

LIS Business Processes, Logistics and Information Systems

ORG Organizing for Performance

MKT Marketing

F\&A Finance and Accounting

STR Strategy and Entrepreneurship 